\title{
Prognostic Value of the Overexpression of Fatty Acid Metabolism-Related Enzymes in Squamous Cell Carcinoma of the Head and Neck
}

\author{
Ying-Wen Su ${ }^{1}$, Pao-Shu Wu ${ }^{2,3, *}$, , Sheng-Hsiang Lin ${ }^{4,5}$, Wen-Yu Huang ${ }^{6}$, Yu-Shao Kuo ${ }^{7}$ \\ and Hung-Pin Lin $3,8, *$ \\ 1 Division of Hematology and Medical Oncology, Department of Internal Medicine, MacKay Memorial \\ Hospital, Taipei 10449, Taiwan; yingwensu.5896@mmh.org.tw \\ 2 Department of Pathology, MacKay Memorial Hospital, Tamsui Branch, New Taipei City 25160, Taiwan \\ 3 MacKay Junior College of Medicine, Nursing, and Management, Taipei 25245, Taiwan \\ 4 Institute of Clinical Medicine and Department of Public Health, College of Medicine, National Cheng Kung \\ University, Tainan 70101, Taiwan; shlin922@mail.ncku.edu.tw \\ 5 Biostatistics Consulting Center, National Cheng Kung University Hospital, College of Medicine, \\ National Cheng Kung University, Tainan 70101, Taiwan \\ 6 Laboratory of Good Clinical Research Center, MacKay Memorial Hospital, Tamsui Branch, New Taipei City \\ 25160, Taiwan; b96608036@ntu.edu.tw \\ 7 School of Chinese Medicine, China Medical University, Taichung 40402, Taiwan; u102023701@cmu.edu.tw \\ 8 Division of Oral Pathology, Department of Stomatology, MacKay Memorial Hospital, Taipei 10449, Taiwan \\ * Correspondence: pw2136@gmail.com (P.-S.W.); hungpin@gmail.com (H.-P.L.)
}

Received: 28 June 2020; Accepted: 16 September 2020; Published: 18 September 2020

check for updates

\begin{abstract}
Reprogramming of cellular energy metabolism, such as lipid metabolism, is a hallmark of squamous cell carcinoma of the head and neck (SCCHN). However, whether protein expression related to fatty acid oxidation (FAO) affects survival in SCCHN remains unclear. We aimed to investigate FAO-related enzyme expression and determine its correlation with clinicopathological variables in SCCHN patients. Immunohistochemical analysis (IHC) of FAO-related protein expression, including carnitine palmitoyltransferase 1 (CPT1), the acyl-CoA dehydrogenase family, and fatty acid synthase (FAS), was performed using tissue microarrays from 102 resected SCCHN tumors. Expressions were categorized according to IHC scores, and the statistical association with clinicopathological factors was determined. Moderate-to-high expression of long-chain acyl-CoA dehydrogenase (LCAD) had a protective role against cancer-related death (adjusted hazard ratio (HR), 0.2; 95\% confidence interval (CI), 0.05-0.87) after covariate adjustment. Age and clinical stage remained independent predictors of survival (adjusted HR, 1.75; 95\% CI, 1.22-2.49 for age; adjusted HR, 14.33; 95\% CI, 1.89-108.60 for stage III/IV disease). Overexpression of medium-chain acyl-CoA dehydrogenase and FAS correlated with advanced tumor stage (T3/T4); however, none of these factors were independent predictors of survival. Several FAO-related enzymes were upregulated and LCAD overexpression had a protective effect on overall survival in advanced SCCHN patients. FAO-related-enzyme expression might have a prognostic impact on survival outcomes in SCCHN.
\end{abstract}

Keywords: fatty acid metabolism; head and neck; squamous cell carcinoma; long-chain acyl-CoA dehydrogenase

\section{Introduction}

Squamous cell carcinoma of the head and neck (SCCHN) is one of the leading causes of cancer-related death globally [1]. One of the hallmarks of SCCHN is the reprogramming of cellular 
energy metabolism [2,3]. SCCHN tumors expressing a high level of phosphorylated acetyl-CoA carboxylase 1 (pACC1) or ACC2 are associated with decreased survival [4,5]. The major cellular function of ACC is to produce malonyl-CoA from acetyl-CoA for fatty acid synthesis [6]. Phosphorylation of ACC inhibits catabolic functions such as lipid storage and causes cellular metabolism to switch to fatty acid oxidation (FAO) [7]. FAO is a catabolic process by which fatty acid molecules are broken down enzymatically. In mammalian cells, FAO primarily occurs in mitochondria except for the oxidation of very-long-chain fatty acids, which occurs in peroxisomes [8]. The major enzymes involved in FAO include carnitine palmitoyltransferase (CPT), the acyl-CoA dehydrogenase family, and hydroxyacyl-CoA dehydrogenase/3-ketoacyl-CoA thiolase/enoyl-CoA hydratase (HADHA). The acyl-CoA dehydrogenase (ACAD) family includes very-long-chain, long-chain, medium-chain, and short-chain acyl-CoA dehydrogenases (VLCAD, LCAD, MCAD, and SCAD, respectively) [9]. In addition to useful intermediates, the final product of FAO is acetyl-CoA, which enters the citric acid cycle in the mitochondrion for energy generation.

Despite the negative correlation of pACC 1 or ACC2 expression with clinical outcome $[4,5]$, it remains unclear whether the expression of the enzymes involved in FAO is associated with cancer progression in SCCHN. Therefore, this study aimed to retrospectively examine the expressions of major enzymes involved in FAO in patients with resected SCCHN and determine the correlation with clinicopathological variables.

\section{Results}

2.1. Incidence of Expression of Fao-Related Proteins in Scchn Tumors and Patient Characteristics According to Survival Status, Age, and Clinical Stage

A total of 102 patients with SCCHN were included in the study between 1 January 2011, and 31 December 2012. The median follow-up time was 5.1 years (interquartile range (IQR), 2.6-6.1). Twenty-nine patients died during the study period. The clinicopathological characteristics of the patients are listed in Table 1.

Table 1. Characteristics of patients $(n=102)$.

\begin{tabular}{cc}
\hline Patient Characteristics & Number (\%) \\
\hline Age, median (range) & $51.96(30.3-86.5)$ \\
\hline$<60$ years & $74(72.5 \%)$ \\
$>60$ years & $28(27.5 \%)$ \\
\hline Gender & $7(6.9 \%)$ \\
\hline Female & $95(93.1 \%)$ \\
Male & \\
\hline Adjuvant treatment & $17(16.7 \%)$ \\
\hline None & $85(83.3 \%)$ \\
Yes & \\
\hline Site & $13(12.7 \%)$ \\
\hline Non-oral cavity & $89(87.3 \%)$ \\
Oral cavity & \\
\hline T & $13(12.7 \%)$ \\
\hline 1 & $31(30.4 \%)$ \\
2 & $23(22.5 \%)$ \\
3 & $35(34.3 \%)$ \\
\hline 4 &
\end{tabular}


Table 1. Cont.

\begin{tabular}{cc}
\hline Patient Characteristics & Number (\%) \\
\hline N & \\
\hline 0 & $49(48.0 \%)$ \\
1 & $19(18.6 \%)$ \\
2 & $31(30.4 \%)$ \\
3 & $3(2.9 \%)$ \\
\hline Stage & \\
\hline I & $8(7.84 \%)$ \\
II & $15(14.71 \%)$ \\
III & $25(24.51 \%)$ \\
IV & $54(52.94 \%)$ \\
\hline HPV P16 & \\
\hline Positive & $13(12.7 \%)$ \\
Negative & $89(87.3 \%)$ \\
\hline
\end{tabular}

T: tumor; N: node; HPV: Human papillomavirus.

Compared with patients who died during the study period, patients who survived were significantly younger (50.64 vs. 56.09 years, $p=0.026$, Mann-Whitney U test), did not have lymph node involvement ( $54.79 \%$ vs. $31.03 \%, p=0.032, \chi^{2}$ test), and were more likely to experience stage $\mathrm{I} / \mathrm{II}$ disease $\left(30.14 \%\right.$ vs. $3.45 \%, p=0.004, \chi^{2}$ test) (Table 2$)$.

Table 2. Correlations between the survival status and patients' characteristics $(n=102)$.

\begin{tabular}{|c|c|c|c|}
\hline Factor & Alive $(n=73)$ & Dead $(n=29)$ & \multirow{2}{*}{$p$-Value } \\
\hline & $n(\%)$ & $n(\%)$ & \\
\hline Age & & & \\
\hline median (IQR) & $50.64(45.13,57.02)$ & $56.09(48.61,67.05)$ & $0.026^{*}$ \\
\hline \multicolumn{4}{|l|}{ Pretreatment fasting sugar } \\
\hline$<100 \mathrm{mg} / \mathrm{dL}$ & $42(57.53)$ & $15(51.72)$ & 0.755 \\
\hline$\geq 100 \mathrm{mg} / \mathrm{dL}$ & $31(42.47)$ & $14(48.28)$ & \\
\hline median (IQR) & $97.00(91.00,105.00)$ & $96.00(87.00,118.00)$ & 0.807 \\
\hline \multicolumn{4}{|l|}{ Pretreatment cholesterol } \\
\hline$<200 \mathrm{mg} / \mathrm{dL}$ & 49 (67.12) & $20(68.97)$ & 1.000 \\
\hline$\geq 200 \mathrm{mg} / \mathrm{dL}$ & $24(32.88)$ & $9(31.03)$ & \\
\hline median (IQR) & $\begin{array}{l}183.00(156.00 \\
208.00)\end{array}$ & $\begin{array}{l}172.00(150.00 \\
202.00)\end{array}$ & 0.404 \\
\hline \multicolumn{4}{|l|}{ Pretreatment triglyceride } \\
\hline$<150 \mathrm{mg} / \mathrm{dL}$ & $58(79.45)$ & $22(75.86)$ & 0.896 \\
\hline$\geq 150 \mathrm{mg} / \mathrm{dL}$ & $15(20.55)$ & $7(24.14)$ & \\
\hline median (IQR) & $109.00(84.00,132.00)$ & $98.00(84.00,129.00)$ & 0.722 \\
\hline \multicolumn{4}{|l|}{ Stage } \\
\hline I/II & $22(30.14)$ & $1(3.45)$ & $0.004 *$ \\
\hline \multicolumn{4}{|l|}{$\mathrm{T}$} \\
\hline $1-2$ & 35 (47.95) & $9(31.03)$ & 0.120 \\
\hline $3-4$ & $38(52.05)$ & $20(68.97)$ & \\
\hline \multicolumn{4}{|l|}{$\mathrm{N}$} \\
\hline 0 & $40(54.79)$ & $9(31.03)$ & $0.032 *$ \\
\hline $1-3$ & $33(45.21)$ & $20(68.97)$ & \\
\hline \multicolumn{4}{|l|}{ FAS } \\
\hline $\begin{array}{l}\text { Negative or low expression } \\
\qquad(0 \sim 1+)\end{array}$ & $61(83.56)$ & $27(93.10)$ & 0.207 \\
\hline $\begin{array}{c}\text { Moderate or strong } \\
\text { expression }(2 \sim 3+) \\
\text { CPT1 }\end{array}$ & $12(16.44)$ & $2(6.90)$ & \\
\hline $\begin{array}{l}\text { Negative to moderate } \\
\text { expression }(0 \sim 2+)\end{array}$ & $63(86.30)$ & $25(86.21)$ & 0.990 \\
\hline Strong expression $(3+)$ & $10(13.70)$ & $4(13.79)$ & \\
\hline
\end{tabular}


Table 2. Cont.

\begin{tabular}{|c|c|c|c|}
\hline Factor & Alive $(n=73)$ & Dead $(n=29)$ & \multirow{2}{*}{$p$-Value ${ }^{a}$} \\
\hline & $n(\%)$ & $n(\%)$ & \\
\hline \multicolumn{4}{|l|}{ MCAD } \\
\hline $\begin{array}{l}\text { Negative to moderate } \\
\text { expression }(0 \sim 2+)\end{array}$ & $51(69.86)$ & $16(55.17)$ & \multirow[t]{2}{*}{0.159} \\
\hline $\begin{array}{l}\text { Strong expression }(3+) \\
\text { LCAD }\end{array}$ & $22(30.14)$ & $13(44.83)$ & \\
\hline $\begin{array}{l}\text { Negative or low expression } \\
\qquad(0 \sim 1+)\end{array}$ & $59(80.82)$ & $27(93.10)$ & \multirow[t]{2}{*}{0.124} \\
\hline $\begin{array}{l}\text { Moderate or strong } \\
\text { expression }(2 \sim 3+)\end{array}$ & $14(19.18)$ & $2(6.90)$ & \\
\hline VLCAD & & & \multirow{4}{*}{0.198} \\
\hline $\begin{array}{l}\text { Negative or low expression } \\
\qquad(0 \sim 1+)\end{array}$ & $65(89.04)$ & $23(79.31)$ & \\
\hline $\begin{array}{c}\text { Moderate or strong } \\
\text { expression }(2 \sim 3+)\end{array}$ & $8(10.96)$ & $6(20.69)$ & \\
\hline HADHA & & & \\
\hline $\begin{array}{l}\text { Negative to moderate } \\
\text { expression }(0 \sim 2+)\end{array}$ & $66(90.41)$ & $24(82.76)$ & \multirow[t]{2}{*}{0.279} \\
\hline Strong expression $(3+)$ & $7(9.59)$ & $5(17.24)$ & \\
\hline
\end{tabular}

${ }^{a} \chi^{2}$ test or Fisher's exact test for categorical variables/Mann-Whitney U test for continuous variables. ${ }^{*} p<0.05$; $n$ : number; IQR: interquartile range; T: tumor; N: node; FAS: fatty acid synthase; CPT1: carnitine palmitoyl transferase 1; MCAD: medium-chain acyl-CoA dehydrogenase; LCAD: long-chain acyl-CoA dehydrogenase; VLCAD: very-long-chain acyl-CoA dehydrogenase; HADHA: hydroxyacyl-CoA dehydrogenase/3-ketoacyl-CoA thiolase/enoyl-CoA hydratase.

We next examined the expressions of FAO-related proteins according to age. None $(0 \%)$ of the 28 patients aged $\geq 60$ years showed a high expression of CPT1A ( $3+$ score), whereas $14(18.92 \%)$ out of 74 patients aged $<60$ years exhibited a high expression of CPT1A ( $3+$ score) $(p=0.01$, Fischer's exact test). However, the negative correlation between CPT1A and age was not further demonstrated by the Spearman correlation analysis (Spearman coefficient for CPT1A and age: $-0.09, p=0.35$ ). There were no statistically significant differences in the levels of pretreatment fasting sugar, cholesterol and triglycerides between both age groups (Table S1).

In terms of clinical stage (Table 3), the incidence of a high expression of MCAD (3+ score) was significantly higher among patients with a more-advanced SCCHN (stage III/IV) (33 of 79 patients, $41.77 \%$ ) than among patients with stage I/II disease ( 2 of 23 patients, $8.70 \%)(p=0.01$, Fisher's exact test). The incidence of high LCAD expression (2+ to 3+ score) was also higher in patients with stage III/IV disease ( 15 of 79 patients, $18.99 \%$ ) than in patients with state I/II disease ( 1 of 23 patients, $4.35 \%$ ), but the differences were not statistically significant $\left(p=0.11, \chi^{2}\right.$ test). Moreover, patients with stage III/IV disease had significantly higher levels of pretreatment fasting sugar than did patients with stage I/II disease (median: 99.00 vs. $92.00 \mathrm{mg} / \mathrm{dl}, p=0.01$, Mann-Whitney U test). However, no significant differences in cholesterol and triglyceride levels were observed between patients with stage I/II disease and patients with stage III/IV disease.

Regarding clinical $\mathrm{T}$ status (Table 4), patients with a higher T stage (T3/T4) were more likely to have a moderate to high FAS expression ( $2+$ to $3+$ score) and high MCAD expression (3+ score) than patients with a lower T stage (T1/T2) (FAS: 12 of 58 patients with T3/T4 stage (20.69\%) vs. 2 of 44 patients with T1/T2 stage (4.55\%), $p=0.04$, Fisher's exact test; MCAD: 27 of 58 patients with T3/T4 stage $(46.55 \%)$ vs. 8 of 44 patients with T1/T2 stage $(18.18 \%), p=0.01, \chi^{2}$ test). Meanwhile, the incidence of increased expressions of CPT1 (3+ score) was high among patients with T3/T4 stage (12 of 58 patients, $20.69 \%$ ) than among patients with T1/T2 stage ( 3 of 44 patients, $6.82 \%$ ), but the difference was not statistically significant ( $p=0.14$, Fisher's exact test). There were no statistically significant differences in the above parameters between the node-negative and node-positive subgroups (Table S2). 
Table 3. Correlations between the clinical staging and patients' characteristics $(n=102)$.

\begin{tabular}{cccc}
\hline Factor & Stage I/II $(n=23)$ & Stage III/IV $(n=79)$ & $p$-Value ${ }^{\text {a }}$ \\
\hline $\begin{array}{c}\text { Age median (IQR) } \\
\text { Pretreatment fasting sugar } \\
\text { median (IQR) }\end{array}$ & $52.64(45.14,63.30)$ & $51.78(45.13 \sim 61.03)$ & 0.87 \\
\hline $\begin{array}{c}\text { Pretreatment cholesterol } \\
\text { median (IQR) }\end{array}$ & $\begin{array}{c}180.00(157.00, \\
201.00)\end{array}$ & $183.00(148.00,208.00)$ & $0.01{ }^{*}$ \\
\hline $\begin{array}{c}\text { Pretreatment triglyceride } \\
\text { median (IQR) }\end{array}$ & $109.00(93.00,152.00)$ & $106.00(83.00,152.00)$ & 0.50 \\
\hline $\begin{array}{c}\text { FAS (2 3+) } \\
n(\%)\end{array}$ & $2(8.70 \%)$ & $12(15.19 \%)$ & 0.73 \\
\hline $\begin{array}{c}\text { CPT1(3+) } \\
n(\%)\end{array}$ & $3(13.0 \%)$ & $11(13.92 \%)$ & 1.00 \\
\hline $\begin{array}{c}\text { MCAD (3+) } \\
n(\%)\end{array}$ & $2(8.70 \%)$ & $33(41.77 \%)$ & $0.01 *$ \\
\hline $\begin{array}{c}\text { LCAD (2 3+) } \\
n(\%)\end{array}$ & $1(4.35 \%)$ & $15(18.99 \%)$ & 0.11 \\
\hline $\begin{array}{c}\text { VLCAD (2 3+) } \\
n(\%)\end{array}$ & $2(8.70 \%)$ & $10(12.66 \%)$ & 1.00
\end{tabular}

a $\chi^{2}$ test or Fisher's exact test for categorical variables/Mann-Whitney $\mathrm{U}$ test for continuous variables. ${ }^{*} p<0.05$; $n$ : number; IQR: interquartile range; T: tumor; N: node; FAS: fatty acid synthase; CPT1: carnitine palmitoyl transferase 1; MCAD: medium-chain acyl-CoA dehydrogenase; LCAD: long-chain acyl-CoA dehydrogenase; VLCAD: very-long-chain acyl-CoA dehydrogenase; HADHA: hydroxyacyl-CoA dehydrogenase/3-ketoacyl-CoA thiolase/enoyl-CoA hydratase.

Table 4. Correlations between T stage and patients' characteristics $(n=102)$.

\begin{tabular}{cccc}
\hline Factor & $\begin{array}{c}\text { T1/T2 } \\
(n=44)\end{array}$ & $\begin{array}{c}\text { T3/T4 } \\
(n=58)\end{array}$ & $p$-Value ${ }^{\text {a }}$ \\
\hline $\begin{array}{c}\text { Age median (IQR) } \\
\text { Pretreatment fasting sugar } \\
\text { median (IQR) }\end{array}$ & $52.67(47.87,63.55)$ & $51.59(42.61,58.43)$ & 0.15 \\
\hline $\begin{array}{c}\text { Pretreatment cholesterol } \\
\text { median (IQR) }\end{array}$ & $188.50(157.00,206.00)$ & $174.00(147.00,204.00)$ & 0.30 \\
\hline $\begin{array}{c}\text { Pretreatment triglyceride } \\
\text { median (IQR) }\end{array}$ & $110.00(93.00,151.50)$ & $100.50(81.00,128.00)$ & 0.13 \\
\hline $\begin{array}{c}\text { FAS (2 3+) } \\
n(\%)\end{array}$ & $2(4.55 \%)$ & $12(20.69 \%)$ & $0.04{ }^{*}$ \\
\hline $\begin{array}{c}\text { CPT1(3+) } \\
n(\%)\end{array}$ & $3(6.82 \%)$ & $11(18.97 \%)$ & 0.14 \\
\hline $\begin{array}{c}\text { MCAD (3+) } \\
n(\%)\end{array}$ & $8(18.18 \%)$ & $27(46.55 \%)$ & 0.01 * \\
\hline $\begin{array}{c}\text { LCAD (2 3+) } \\
n(\%)\end{array}$ & $7(15.91 \%)$ & $9(15.52 \%)$ & 1.00 \\
\hline $\begin{array}{c}\text { VLCAD (2 3+) } \\
n(\%)\end{array}$ & $4(9.09 \%)$ & $10(17.24 \%)$ & 0.37 \\
\hline $\begin{array}{c}\text { HADHA }(3+) \\
n(\%)\end{array}$ & $3(6.82 \%)$ & $9(15.52 \%)$ & 0.30 \\
\hline
\end{tabular}

${ }^{a} \chi^{2}$ test or Fisher's exact test for categorical variables/Mann-Whitney $\mathrm{U}$ test for continuous variables. ${ }^{*} p<0.05$; $n$ : number; IQR: interquartile range; T: tumor; N: node; FAS: fatty acid synthase; CPT1: carnitine palmitoyl transferase 1; MCAD: medium-chain acyl-CoA dehydrogenase; LCAD: long-chain acyl-CoA dehydrogenase; VLCAD: very-long-chain acyl-CoA dehydrogenase; HADHA: hydroxyacyl-CoA dehydrogenase/3-ketoacyl-CoA thiolase/enoyl-CoA hydratase. 
We also examined the correlation of FAO-related enzyme expression with either human papillomavirus (HPV) infection status or tumor proliferation activity. As shown in Tables S3 and S4, there was no statistically significant difference of FAO-related protein expression in HPV-positive vs. HPV-negative tumor or in tumor with high vs. low proliferation index (Ki-67 $\geq 10 \%$ vs. Ki-67 < 10\%).

\subsection{Univariate and Multivariable Cox Regression Analyses}

In the univariate Cox regression analysis, increased age and advanced stage were significantly correlated with poor survival outcomes (crude hazard ratio (HR), 1.49 (95\% confidence interval (CI), 1.11-1.98) and 9.59 (95\% CI, 1.30-70.51), respectively) (Table 5). We ran a multicollinearity analysis, which showed no collinearity among the covariates (variance inflation factors (VIF) $<1.8$, Table 5). After multivariate adjustment, the risk for cancer-related death remained high with increased age and advanced clinical stage (adjusted HR, 1.75 (95\% CI, 1.22-2.49) and 14.33 (95\% CI, 1.89-108.60), respectively). Moreover, overexpression of LCAD (2+ to 3+ score) had an independent protective role against cancer-related death (adjusted HR, 0.2; 95\% CI, 0.05-0.87).

Table 5. Crude and adjusted HRs with $95 \%$ CIs for mortality related to clinical parameters and fatty acid oxidation-related expression of enzymes. Total case $(n=102)$.

\begin{tabular}{|c|c|c|c|c|}
\hline Factor & $\begin{array}{l}\text { Crude HR } \\
(95 \% \text { CI })\end{array}$ & $p$-Value & $\begin{array}{c}\text { Adjusted HR } \\
(95 \% \text { CI) }\end{array}$ & $p$-Value \\
\hline Age, per 10 years & $1.49(1.11-1.98)$ & 0.007 * & $1.75(1.22-2.49)$ & $0.002 *$ \\
\hline \multicolumn{5}{|l|}{ Pretreatment fasting sugar } \\
\hline$\geq 100$ vs. $<100$ (mg/dL) & $1.12(0.54-2.31)$ & 0.770 & $0.63(0.29-1.37)$ & 0.245 \\
\hline Stage: III/IV vs. I/II & $9.59(1.30-70.51)$ & $0.026^{*}$ & $14.33(1.89-108.60)$ & 0.010 * \\
\hline FAS: $2 \sim 3+$ vs. $0 \sim 1+$ & $0.41(0.10-1.75)$ & 0.232 & $0.33(0.08-1.42)$ & 0.135 \\
\hline MCAD: 3+ vs. 0 2+ & $1.75(0.84-3.65)$ & 0.133 & $1.30(0.62-2.73)$ & 0.495 \\
\hline LCAD: 2 3+ vs. $0 \sim 1+$ & $0.36(0.09-1.51)$ & 0.161 & $0.20(0.05-0.87)$ & $0.032 *$ \\
\hline VLCAD: $2 \sim 3+$ vs. $0 \sim 1+$ & $1.57(0.64-3.85)$ & 0.328 & $1.26(0.49-3.21)$ & 0.635 \\
\hline HADHA: 3+ vs. 0 2+ & $1.54(0.58-4.04)$ & 0.385 & $0.74(0.27-2.01)$ & 0.549 \\
\hline
\end{tabular}

Variance inflation factors (VIF) values: Age: 1.32, Pretreatment fasting sugar: 1.08, Stage: 1.03, FAS: 1.34, MCAD: 1.55, LCAD: 1.28 , VLCAD: 1.08 , HADHA: $1.18 .{ }^{*} p<0.05$.

In patients with stage III/IV SCCHN $(n=78)$, the risk of death was high among those with advanced age (adjusted HR, 1.59; 95\% CI, 1.10-2.29) but low among those who had a moderate to high expression of LCAD (adjusted HR, 0.21; 95\% CI, 0.05-091) (Table 6). However, the HRs of death did not differ significantly in terms of overexpression of other FAO-related proteins such as MCAD in patients with stage III/IV disease.

Table 6. Crude and adjusted HRs with $95 \%$ CIs for mortality related to clinical parameters and fatty acid oxidation-related expression of enzymes. Stage III/IV case $(n=79)$.

\begin{tabular}{|c|c|c|c|c|}
\hline Factor & $\begin{array}{c}\text { Crude HR } \\
(95 \% \text { CI })\end{array}$ & $p$-Value & $\begin{array}{c}\text { Adjusted HR } \\
(95 \% \text { CI })\end{array}$ & $p$-Value \\
\hline Age, per 10 years & $1.53(1.10-2.12)$ & $0.012 *$ & $1.59(1.10-2.29)$ & 0.014 * \\
\hline $\begin{array}{l}\text { Pretreatment fasting sugar: } \\
\quad \geq 100 \text { vs. }<100 \mathrm{mg} / \mathrm{dL}\end{array}$ & $0.95(0.45-1.99)$ & 0.885 & $0.72(0.33-1.56)$ & 0.401 \\
\hline FAS: $2 \sim 3+$ vs. $0 \sim 1+$ & $0.17(0.02-1.21)$ & 0.077 & $0.15(0.02-1.13)$ & 0.066 \\
\hline MCAD: 3+ vs. 0 2+ & $1.34(0.64-2.82)$ & 0.439 & $1.36(0.64-2.90)$ & 0.431 \\
\hline LCAD: $2 \sim 3+$ vs. $0 \sim 1+$ & $0.28(0.07-1.18)$ & 0.084 & $0.21(0.05-0.91)$ & 0.037 * \\
\hline VLCAD: $2 \sim 3+$ vs. $0 \sim 1+$ & $1.46(0.59-3.60)$ & 0.415 & $1.41(0.54-3.64)$ & 0.483 \\
\hline HADHA: 3+ vs. 0 2+ & $1.44(0.55-3.80)$ & 0.460 & $0.80(0.29-2.20)$ & 0.668 \\
\hline
\end{tabular}

VIF values: Age: 1.33, Pretreatment fasting sugar: 1.08, FAS: 1.34, MCAD: 1.60, LCAD: 1.29, VLCAD: 1.09, HADHA: 1.18. ${ }^{*} p<0.05$. 
Similar results were observed in patients with $\mathrm{T} 3 / \mathrm{T} 4$ stage $(n=58)$. The risk of death was high among those with advanced age (adjusted $\mathrm{HR}, 1.92 ; 95 \% \mathrm{CI}, 1.16-3.18$ ) but low among those who had a moderate to high expression of LCAD (adjusted HR, 0.09; 95\% CI, 0.01-085) (Table 7).

Table 7. Crude and adjusted HRs with $95 \%$ CIs for mortality related to clinical parameters and fatty acid oxidation-related expression of enzymes. T3/T4 case $(n=58)$.

\begin{tabular}{|c|c|c|c|c|}
\hline Factor & $\begin{array}{l}\text { Crude HR } \\
(95 \% \mathrm{CI})\end{array}$ & $p$-Value & $\begin{array}{l}\text { Adjusted HR } \\
\quad(95 \% \mathrm{CI})\end{array}$ & $p$-Value \\
\hline Age, per 10 years & $1.46(1.01-2.12)$ & $0.047^{*}$ & $1.92(1.16-3.18)$ & $0.012 *$ \\
\hline $\begin{array}{l}\text { Pretreatment fasting sugar: } \\
\geq 100 \text { vs. }<100 \mathrm{mg} / \mathrm{dL}\end{array}$ & $0.67(0.28-1.61)$ & 0.369 & $0.41(0.16-1.07)$ & 0.069 \\
\hline FAS: $2 \sim 3+$ vs. $0 \sim 1+$ & $0.16(0.02-1.19)$ & 0.073 & $0.13(0.02-1.00)$ & 0.050 \\
\hline MCAD: 3+ vs. 0 2+ & $1.00(0.42-2.42)$ & 0.997 & $1.16(0.46-2.92)$ & 0.757 \\
\hline LCAD: 2 3+ vs. $0 \sim 1+$ & $0.24(0.03-1.78)$ & 0.162 & $0.09(0.01-0.85)$ & $0.035^{*}$ \\
\hline VLCAD: $2 \sim 3+$ vs. $0 \sim 1+$ & $1.51(0.55-4.16)$ & 0.425 & $0.99(0.32-3.11)$ & 0.989 \\
\hline HADHA: 3+ vs. 0 2+ & $1.22(0.41-3.66)$ & 0.723 & $0.44(0.13-1.50)$ & 0.187 \\
\hline
\end{tabular}

\section{Discussion}

In this retrospective study, we found that moderate to high expression of LCAD had a protective role against cancer-related death after adjustment for clinical variables such as age and stage. Overexpression of MCAD and FAS were correlated with an advanced tumor stage (T3/T4), however, none of these factors were independent predictors of survival.

Previous studies on cellular metabolism in SCCHN have revealed dysregulation in multiple metabolic pathways in tumors, such as the mitochondrial oxidative phosphorylation and the tricarboxylic acid cycle [10], and in the utilization of glucose as a dominant energy source for the survival and proliferation of SCCHN cells [11]. Despite the endeavors in targeting aerobic glycolysis in the treatment of SCCHN, no glycolytic inhibitors have been used in the clinical setting so far [12], suggesting that SCCHN cells might have alternative metabolic pathways to acquire energy to survive. Our previous study, and a study by another group, have shown that overexpression of phosphorylated inhibitory ACC1 or ACC2 was associated with a decreased survival rate in SCCHN $[4,5]$. Since the major function of ACC1 is to regulate fatty acid metabolism, and ACC2 regulates FAO [13,14], the reprograming of lipid metabolism may play a role in tumor progression.

LCAD is a mitochondrial enzyme that catalyzes the initial step of FAO [15]. Although LCAD belongs to the ACAD protein family, the exact physiological role of LCAD in FAO remains to be elucidated. In humans, VLCAD, MCAD, and SCAD are specific to large, medium, and short chain acyl-CoAs, respectively. In contrast, LCAD has broad substrate specificity and is active with not only medium and long chain acyl-CoAs but also branched-chain acetyl CoA [16]. The overlapped substrate activity suggests that LCAD might play less-important roles in FAO in humans $[17,18]$. Recently, Zhang et al. showed a unique role of LCAD in FAO-driven oxidative signaling, which does not exist in other ACAD family members [19]. This suggests LCAD may have a distinct function in control of cell proliferation. Despite using different scoring systems, immunohistochemistry (IHC) studies have found a high expression of LCAD in $45-50 \%$ of patients with hepatocellular carcinoma (HCC) [20,21] and in $48.9 \%$ of patients with esophageal squamous cell carcinoma [22]. A low expression or methylation of LCAD has been associated with poor survival outcomes in several cancers such as HCC and breast cancer [20,21,23]. At the cellular level, LCAD can be inhibited by sirtuin 3 acetylation or by hypoxia-inducible factor- $1 \alpha$ under hypoxic conditions [20,24]. In HCC cells, loss of LCAD has been shown to promote tumor progression as a consequence of the activation of Yap [21] or reduction 
of phosphatase and tensin homolog [20], while overexpression of LCAD has been shown to inhibit tumor growth [20], indicating that LCAD has tumor-suppressive functions. This was supported by our data that LCAD had a protective role against cancer-related death (adjusted HR: 0.2; 95\% CI, 0.05-0.87) after covariate adjustment (Table 5A). Furthermore, we also observed numerically increased expression of LCAD in patients with advanced stages (III and IV) of cancer (Table 3). However, this numeric difference was not statistically significant. Thus, selection bias or other confounding factors may have existed in the study cohort. This finding might explain the protective effect of LCAD expression in SCCHN, which was only observed after all covariate adjustment in the multivariate analysis. How LCAD is expressed in more patients with advanced disease but also exerts a protective role in their outcomes remains to be studied. Since only a small portion (19.23\%) of advanced disease tissues overexpressed LCAD, whether such patients have different cellular control of the tumor proliferation rate, or sensitivity to chemotherapy or irradiation, needs to be investigated with larger clinical samples.

Our results also showed that the expression of MCAD and FAS increased as the tumor progressed from T1/T2 to T3/T4. MCAD also catalyzes mitochondrial FAO. MCAD deficiency is a potentially lethal inherited disease in neonates that may lead to hepatic dysfunction, fasting hypoglycemia, encephalopathy, or infant death [25]. Although the correlation between MCAD expression and cancer-related death was not observed in our multivariate analysis, a previous study has shown that a high expression of MCAD was associated with a better overall survival (OS) in neuroblastoma patients [26].

In this study, we also examined the expressions of FAS, an enzyme responsible for the endogenous synthesis of fatty acids, because several previous studies have shown that its overexpression was associated with poor prognosis, higher histologic grade, and nodal metastasis in SCCHN [27,28]. Consistent with the results of one of these studies [27], higher expressions of FAS in our patients was not an independent prognostic factor for survival after adjustment for other clinicopathological factors, despite its association with an advanced clinical $\mathrm{T}$ stage.

In summary, this study revealed that lipid metabolism is deranged in SCCHN, since several enzymes involved in FAO were upregulated in the advanced stage of the disease. In particular, we found that LCAD overexpression had a protective role for overall survival. The expression of these FAO-related enzymes might have a prognostic impact on survival outcomes in SCCHN. Although recent studies have shown that FAO is dysregulated in various tumor tissues [29] and that activating FAO will have a negative impact on tumor growth and progression, and will result in a more favorable clinical outcome [26,29-31], no in vitro study has determined the fate of SCCHN cells under an increased rate of FAO. Nevertheless, the present study was limited by its retrospective nature, small number of cases studied, and the semi-quantitative assessment of protein expression by immunohistochemistry. Further elucidation of the roles of FAO-related enzymes in SCCHN may hold promise for better management of the disease.

\section{Materials and Methods}

\subsection{Ethics Statement}

Samples were acquired after written informed consent was obtained from the participants. This study was approved by the Ethics Committee of Mackay Memorial Hospital (approval no. 16MMHIS070e and 18MMHIS197e).

\subsection{Study Subjects and Tissue Microarray Construction}

In this retrospective study, we collected data on 150 patients who underwent surgery for squamous cell carcinoma of the oral cavity, oropharynx, hypopharynx, or larynx at Mackay Memorial Hospital, Taiwan, between January 1, 2011, and December 31, 2012. We excluded patients whose tumors were recurrent $(n=23)$, who had other concurrent primary cancer $(n=7)$, who had prior exposure to neoadjuvant chemotherapy $(n=4)$, who did not receive definitive radical surgery $(n=9)$, who died 
within 2 months after surgery $(n=3)$, and who were lost to follow-up $(n=2)$. Therefore, 102 patients were included in the analysis. Formalin-fixed paraffin-embedded surgical tumor samples and paired normal mucosal tissues ( $3 \mu \mathrm{m}$ thickness) were arrayed in quadruplicate for tissue microarray analysis. A chart review was conducted to retrieve clinicopathological information, including demographics, tumor-node-metastasis (TNM) stage, and OS. TNM staging was evaluated according to the guidelines of the American Joint Committee on Cancer, Eighth Edition (2017) [32]. Patients were monitored until death or until January 1,2018, whichever was earlier. The baseline characteristics of the patients are listed in Table 1.

\subsection{Immunohistochemistry and Scoring}

Immunohistochemistry (IHC) of both tumor and paired normal mucosal tissues was performed as previously described [33]. Primary antibodies against FAS, CPT1A, MCAD, LCAD, VLCAD, and HADHA were obtained from Abcam (Cambridge, UK). Histopathological differentiation and expression of these proteins were evaluated independently by two pathologists (PS Wu and HP Lin) and quantified as previously described $[4,33]$. A composite score using the staining intensity $(0,1+, 2+$, and $3+$ ) and the percentage of the area showing reactivity was generated. Scores were averaged over replicate cores to obtain the final IHC score for each tumor. Representative examples of each score are presented in Figure 1. HPV p16 expression was evaluated with a CINtec p16 Histology kit following the manufacturer's instructions (Ventana, Tucson, AZ, USA). Anti-Ki-67 antibody was obtained from Thermo Fisher Scientific (Waltham, MA, USA). Ki-67 expression was assessed based on percentage of positive nuclear staining in tumor regions. 

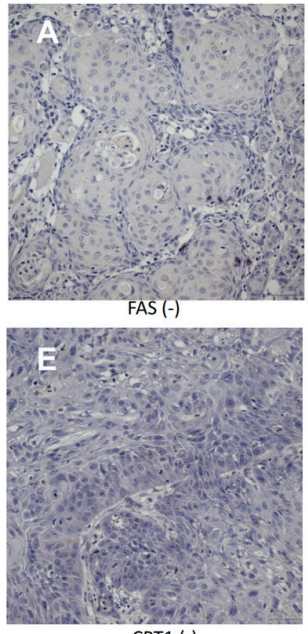

CPT1 $1-$
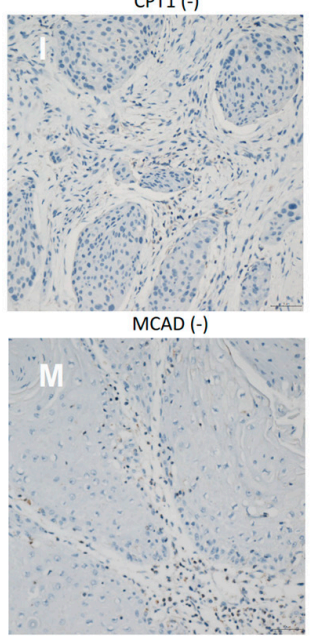

LCAD (-)

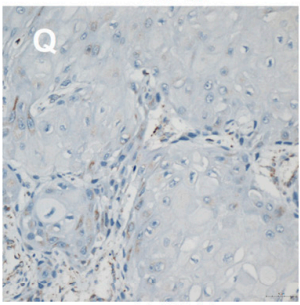

$\operatorname{VLCAD}(-)$

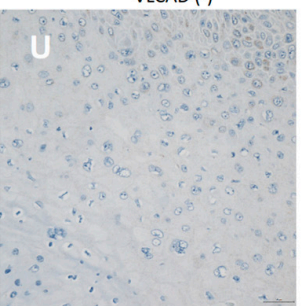

HADHA (-)
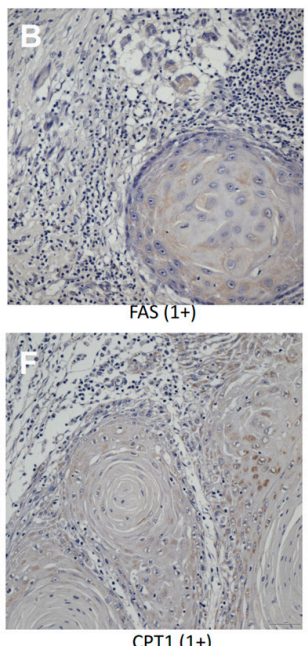

CPT1 (1+)

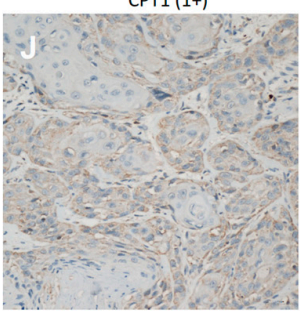

MCAD (1+)

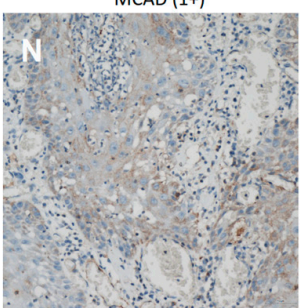

LCAD (1+)

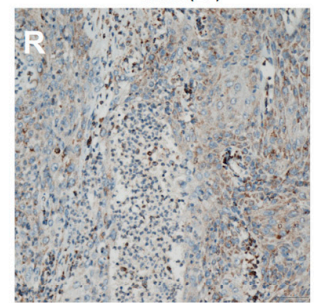

$\operatorname{VLCAD}(1+)$

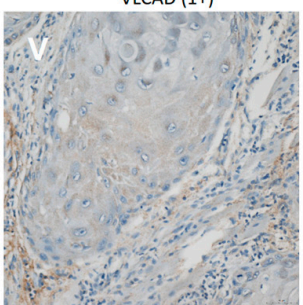

HADHA (1+)

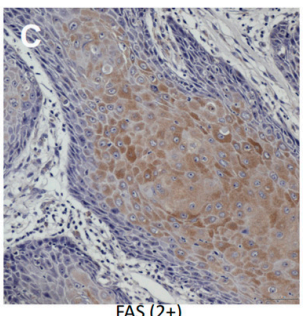

FAS $(2+)$

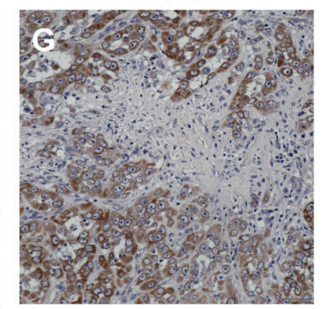

CPT1 (2+)

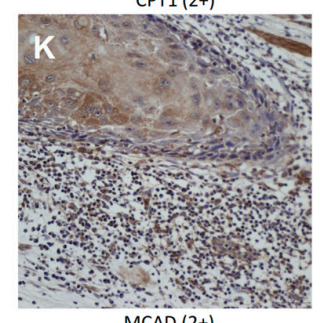

$\operatorname{MCAD}(2+$

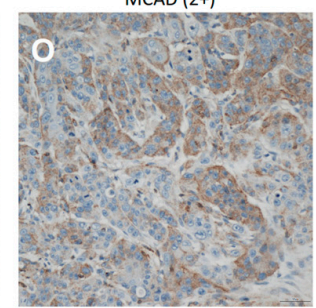

$\operatorname{LCAD}(2+)$

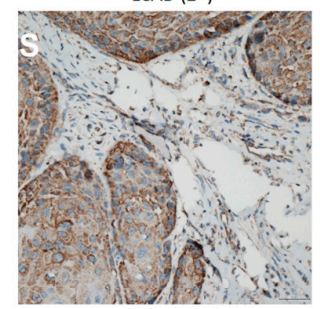

VLCAD (2+)

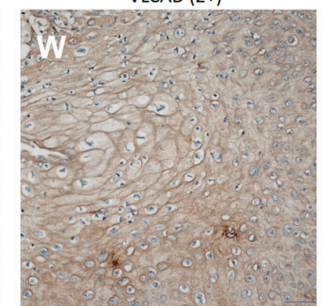

HADHA (2+)
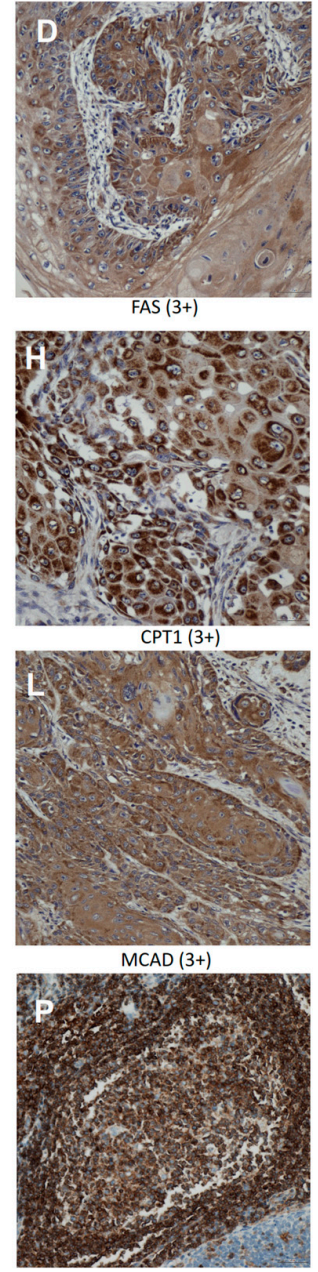

$\operatorname{LCAD}(3+)$

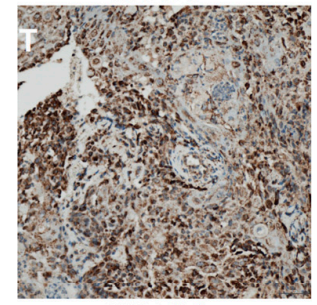

VLCAD (3+)

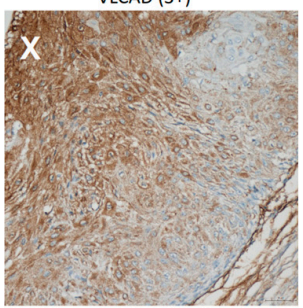

HADHA (3+)

Figure 1. Representative immunohistochemical staining scores of antibodies used in the specimens of squamous cell carcinoma of the head and neck. All proteins were predominantly expressed in the cytoplasm of tumor cells. (A-D) fatty acid synthase (FAS) staining (0 to 3+), (D-H) carnitine palmitoyltransferase 1 (CPT1) staining (0 to $3+)$, (I-L) medium-chain acyl-CoA dehydrogenase (MCAD) staining (0 to $3+$ ), (M-P) long-chain acyl-CoA dehydrogenase (LCAD) staining (0 to $3+)$, (Q-T) very-long-chain acyl-CoA dehydrogenase (VLCAD) staining (0 to $3+$ ), and (U-X) hydroxyacyl-CoA dehydrogenase/3-ketoacyl-CoA thiolase/enoyl-CoA hydratase (HADHA) staining (0 to $3+$ ), (magnification 200×). 


\subsection{Statistical Analysis}

Baseline variables with a continuous outcome were expressed as medians and interquartile ranges (IQRs), and discrete variables as frequencies and percentages. To determine the associations between the expression of FAO-related enzymes and clinicopathological features, we performed the chi-squared $\left(\chi^{2}\right)$ test or Fisher's exact test to compare categorical variables and the Mann-Whitney U test to compare continuous variables. Baseline characteristics associated with cancer-related deaths were estimated using univariable Cox regression models and reported as crude hazard ratios (HRs) with $95 \%$ confidence intervals (CIs). To assess the presence of multicollinearity, variance-inflation factors (VIF) were checked. All VIFs for the covariates were low, indicating that no multicollinearity existed among these variables. To adjust for covariates, we calculated HRs by including independent baseline characteristics in the multivariable Cox regression model. All models incorporated cancer-related death as a dependent variable and baseline characteristics as independent variables, and the timeframe was from the date of the first anti-cancer treatment to the date of death or the last follow-up. All analyses were conducted using SAS software version 9.4 (SAS Institute, Cary, NC, USA). All statistical tests were two-sided, and significance was defined as a $p$-value of $<0.05$.

\section{Conclusions}

In conclusion, we showed several enzymes involved in FAO were upregulated in patients with advanced SCCHN, whereas LCAD overexpression showed a protective role for overall survival in these patients. The expression of these FAO-related enzymes might have a prognostic impact on survival outcomes in SCCHN.

Supplementary Materials: The following are available online at http://www.mdpi.com/1422-0067/21/18/6851/s1.

Author Contributions: Y.-W.S. contributed to the conception and design of the study. Y.-W.S., P.-S.W., and H.-P.L. collected patients' clinical data and drafted the manuscript. W.-Y.H. and Y.-S.K. performed the research. Y.-W.S., S.-H.L., and P.-S.W. analyzed the data. H.-P.L. and Y.-S.K. helped in revising the manuscript. All authors have read and agreed to the published version of the manuscript.

Funding: This work was supported by the Mackay Memorial Hospital, grant nos. MMH-106-94 and MMH-108-78 and the Ministry of Science and Technology, grant no. MOST-108-2314-B-195-004.

Acknowledgments: We thank the Department of Pathology at Mackay Memorial Hospital for the preparation of the pathology slides and for the immunohistochemistry equipment.

Conflicts of Interest: The authors declare no conflict of interest.

\section{Abbreviations}

$\begin{array}{ll}\text { ACAD } & \text { acyl-CoA dehydrogenase } \\ \text { ACC } & \text { acetyl-CoA carboxylase } \\ \text { CI } & \text { confidence interval } \\ \text { CPT1 } & \text { carnitine palmitoyltransferase 1 } \\ \text { FAO } & \text { fatty acid oxidation } \\ \text { FAS } & \text { fatty acid synthase } \\ \text { HADHA } & \text { hydroxyacyl-CoA dehydrogenase/3-ketoacyl-CoA thiolase/enoyl-CoA hydratase } \\ \text { HCC } & \text { hepatocellular carcinoma } \\ \text { HPV } & \text { Human Papillomavirus } \\ \text { HR } & \text { hazard ratio } \\ \text { IHC } & \text { immunohistochemistry } \\ \text { IQR } & \text { interquartile range } \\ \text { LCAD } & \text { long-chain acyl-CoA dehydrogenase } \\ \text { MCAD } & \text { medium-chain acyl-CoA dehydrogenase } \\ \text { OS } & \text { overall survival } \\ \text { pACC1 } & \text { phosphorylated acetyl-CoA carboxylase 1 }\end{array}$




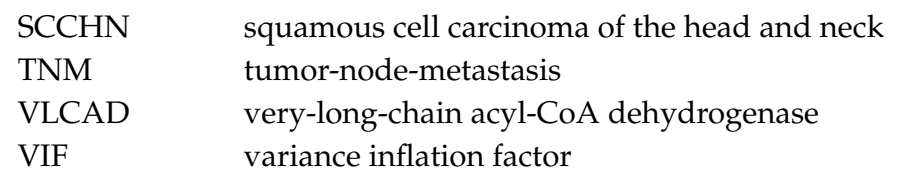

\section{References}

1. Bray, F.; Ferlay, J.; Soerjomataram, I.; Siegel, R.L.; Torre, L.A.; Jemal, A. Global cancer statistics 2018: GLOBOCAN estimates of incidence and mortality worldwide for 36 cancers in 185 countries. CA Cancer J. Clin. 2018, 68, 394-424. [CrossRef] [PubMed]

2. Hanahan, D.; Weinberg, R.A. Hallmarks of cancer: The next generation. Cell 2011, 144, 646-674. [CrossRef]

3. Cruz-Gregorio, A.; Martinez-Ramirez, I.; Pedraza-Chaverri, J.; Lizano, M. Reprogramming of energy metabolism in response to radiotherapy in head and neck squamous cell carcinoma. Cancers 2019, 11, 182. [CrossRef]

4. Su, Y.W.; Lin, Y.H.; Pai, M.H.; Lo, A.C.; Lee, Y.C.; Fang, I.C. Association between phosphorylated AMP-activated protein kinase and acetyl-CoA carboxylase expression and outcome in patients with squamous cell carcinoma of the head and neck. PLoS ONE 2014, 9, e96183. [CrossRef] [PubMed]

5. Li, K.; Zhang, C.; Chen, L.; Wang, P.; Fang, Y.; Zhu, J. The role of acetyl-coA carboxylase2 in head and neck squamous cell carcinoma. Peer J. 2019, 7, e7037. [CrossRef] [PubMed]

6. Ronnebaum, S.M.; Joseph, J.W.; Ilkayeva, O.; Burgess, S.C.; Lu, D.; Becker, T.C. Chronic suppression of acetyl-CoA carboxylase 1 in beta-cells impairs insulin secretion via inhibition of glucose rather than lipid metabolism. J. Biol. Chem. 2008, 283, 14248-14256. [CrossRef] [PubMed]

7. Glatzel, D.K.; Koeberle, A.; Pein, H.; Loser, K.; Stark, A.; Keksel, N. Acetyl-CoA carboxylase 1 regulates endothelial cell migration by shifting the phospholipid composition. J. Lipid Res. 2018, 59, 298-311. [CrossRef] [PubMed]

8. Houten, S.M.; Wanders, R.J.A. A general introduction to the biochemistry of mitochondrial fatty acid ß-oxidation. J. Inherit. Metab. Dis. 2010, 33, 469-477. [CrossRef]

9. Lin, H.; Patel, S.; Affleck, V.S.; Wilson, I.; Turnbull, D.M.; Joshi, A.R. Fatty acid oxidation is required for the respiration and proliferation of malignant glioma cells. Neuro Oncol. 2017, 19, 43-54. [CrossRef]

10. Tripathi, P.; Kamarajan, P.; Somashekar, B.S.; MacKinnon, N.; Chinnaiyan, A.M.; Kapila, Y.L. Delineating metabolic signatures of head and neck squamous cell carcinoma: Phospholipase A2, a potential therapeutic target. Int. J. Biochem. Cell Biol. 2012, 44, 1852-1861. [CrossRef]

11. Sandulache, V.C.; Ow, T.J.; Pickering, C.R.; Frederick, M.J.; Zhou, G.; Fokt, I. Glucose, not glutamine, is the dominant energy source required for proliferation and survival of head and neck squamous carcinoma cells. Cancer 2011, 117, 2926-2938. [CrossRef] [PubMed]

12. Hsieh, Y.T.; Chen, Y.F.; Lin, S.C.; Chang, K.W.; Li, W.C. Targeting cellular metabolism modulates head and neck oncogenesis. Int. J. Mol. Sci. 2019, 20, 3960. [CrossRef] [PubMed]

13. Abu-Elheiga, L.; Matzuk, M.M.; Abo-Hashema, K.A.; Wakil, S.J. Continuous fatty acid oxidation and reduced fat storage in mice lacking acetyl-CoA carboxylase 2. Science 2001, 291, 2613-2616. [CrossRef]

14. Kim, T.S.; Leahy, P.; Freake, H.C. Promoter usage determines tissue specific responsiveness of the rat acetyl-CoA carboxylase gene. Biochem. Biophys. Res. Commun. 1996, 225, 647-653. [CrossRef] [PubMed]

15. Lea, W.; Abbas, A.S.; Sprecher, H.; Vockley, J.; Schulz, H. Long-chain acyl-CoA dehydrogenase is a key enzyme in the mitochondrial beta-oxidation of unsaturated fatty acids. Biochim. Biophys. Acta 2000, 1485, 121-128. [CrossRef]

16. He, M.; Pei, Z.; Mohsen, A.; Watkins, P.; Murdoch, G.; Veldhoven, P.P.V.; Ensenauer, R.; Vockley, J. Identification and characterization of new long chain acyl-CoA dehydrogenases. Mol. Genet. Metab. 2011, 102, 418-429. [CrossRef]

17. Chegary, M.; Brinke, H.; Ruiter, J.P.N.; Wijburg, F.A.; Stoll, M.S.K.; Minkler, P.E. Mitochondrial long chain fatty acid beta-oxidation in man and mouse. Biochim. Biophys. Acta 2009, 1791, 806-815. [CrossRef]

18. Maher, A.C.; Mohsen, A.W.; Vockley, J.; Tarnopolsky, M.A. Low expression of long-chain acyl-CoA dehydrogenase in human skeletal muscle. Mol. Genet. Metab. 2010, 100, 163-167. [CrossRef]

19. Zhang, Y.; Bharathi, S.S.; Beck, M.E.; Goetzmanet, E.S. The fatty acid oxidation enzyme long-chain acyl-CoA dehydrogenase can be a source of mitochondrial hydrogen peroxide. Redox. Biol. 2019, 26, 101253. [CrossRef] 
20. Huang, D.; Li, T.; Li, X.; Zhang, L.; Sun, L.; He, X. HIF-1-mediated suppression of acyl-CoA dehydrogenases and fatty acid oxidation is critical for cancer progression. Cell Rep. 2014, 8, 1930-1942. [CrossRef]

21. Zhao, X.; Qin, W.; Jiang, Y.; Yang, Z.; Yuan, B.; Dai, R. ACADL plays a tumor-suppressor role by targeting Hippo/YAP signaling in hepatocellular carcinoma. NPJ Precis Oncol. 2020, 4, 7. [CrossRef] [PubMed]

22. Yu, D.L.; Li, H.W.; Wang, Y.; Li, C.Q.; You, D.; Jiang, L. Acyl-CoA dehydrogenase long chain expression is associated with esophageal squamous cell carcinoma progression and poor prognosis. Oncol. Targets Ther. 2018, 11, 7643-7653. [CrossRef] [PubMed]

23. Hill, V.K.; Ricketts, C.; Bieche, I.; Vacher, S.; Gentle, D.; Lewis, C. Genome-wide DNA methylation profiling of CpG islands in breast cancer identifies novel genes associated with tumorigenicity. Cancer Res. 2011, 71, 2988-2999. [CrossRef] [PubMed]

24. Hirschey, M.D.; Shimazu, T.; Goetzman, E.; Jing, E.; Schwer, B.; Lombard, D.B. SIRT3 regulates mitochondrial fatty-acid oxidation by reversible enzyme deacetylation. Nature 2010, 464, 121-125. [CrossRef]

25. Chen, Z.; Liu, R.; Che, J.; Shi, H.; Hou, Y.; Liu, Y. Qualitative and quantitative studies on human B7.1-Fc fusion protein and the application in pharmacokinetic study in rhesus monkeys. J. Pharm. Biomed. Anal. 2011, 54, 133-140. [CrossRef] [PubMed]

26. Hsieh, C.H.; Cheung, C.H.Y.; Liu, Y.L.; Hou, C.L.; Hsu, C.L.; Huang, C.T. Quantitative proteomics of Th-MYCN transgenic mice reveals aurora kinase inhibitor altered metabolic pathways and enhanced ACADM to suppress neuroblastoma progression. J Proteome Res. 2019, 18, 3850-3866. [CrossRef]

27. Silva, S.D.; Perez, D.E.; Nishimoto, I.N.; Alves, F.A.; Pinto, C.A.L.; Kowalski, L.P. Fatty acid synthase expression in squamous cell carcinoma of the tongue: Clinicopathological findings. Oral. Dis. 2008, 14, 376-382. [CrossRef]

28. Agostini, M.; Almeida, L.Y.; Bastos, D.C.; Ortega, R.M.; Moreira, F.S.; Seguin, F. The fatty acid synthase inhibitor orlistat reduces the growth and metastasis of orthotopic tongue oral squamous cell carcinomas. Mol. Cancer Ther. 2014, 13, 585-595. [CrossRef]

29. Aiderus, A.; Black, M.A.; Dunbier, A.K. Fatty acid oxidation is associated with proliferation and prognosis in breast and other cancers. BMC Cancer 2018, 18, 805. [CrossRef]

30. Hardy, S.; El-Assaad, W.; Przybytkowski, E.; Joly, E.; Prentki, M.; Langelier, Y. Saturated fatty acid-induced apoptosis in MDA-MB-231 breast cancer cells. A role for cardiolipin. J. Biol. Chem. 2003, 278, 31861-31870. [CrossRef]

31. Padanad, M.S.; Konstantinidou, G.; Venkateswaran, N.; Melegari, M.; Rindhe, S.; Mitsche, M. Fatty acid oxidation mediated by acyl-CoA synthetase long chain 3 is required for mutant KRAS lung tumorigenesis. Cell Rep. 2016, 16, 1614-1628. [CrossRef] [PubMed]

32. Lydiatt, W.; O'Sullivan, B.; Patel, S. Major changes in head and neck staging for 2018. Am. Soc. Clin. Oncol. Educ. Book 2018, 38, 505-514. [CrossRef] [PubMed]

33. Chen, C.L.; Chiang, C.Y.; Liao, K.W.; Ho, S.Y.; Chang, Y.F.; Lim, K.H. cIAP-2 expression increases in elderly patients with squamous cell carcinoma of the head and neck. Int. J. Gerontol. 2017, 11, 22-26. [CrossRef]

(C) 2020 by the authors. Licensee MDPI, Basel, Switzerland. This article is an open access article distributed under the terms and conditions of the Creative Commons Attribution (CC BY) license (http://creativecommons.org/licenses/by/4.0/). 